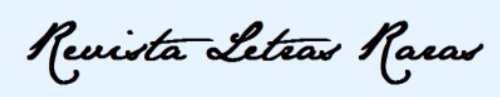

ISSN: 2317-2347 - v. 7, n. 1 (2018)

\title{
Pareceristas AD. HOC
}

\section{Ana Lúcia Rocha Silva}

Possui graduação em Direito pela Universidade Ceuma (2003), graduação em Licenciatura em Letras pela Universidade Federal do Maranhão (1981), mestrado em Linguística pela Universidade Federal do Ceará (2009) e doutorado em Linguística pela Universidade Federal do Ceará (2014). Professora assistente do dep. de letras da Universidade Federal do Maranhão, atualmente leciona Língua Portuguesa em diversos períodos. Tem experiência na área de Letras, com ênfase em Letras, atuando principalmente nos seguintes temas: leitura em língua portuguesa, aquisição da linguagem, morfologia derivacional, escolas, justiça trabalho, projeto, pedagógico e linguística aplicada ao ensino de língua portuguesa.

Link Currículo Lattes:

http://buscatextual.cnpq.br/buscatextual/visualizacv.do?id=K4244269T2

\section{Cristiane Navarrete Tolomei}

Pós-doutora em Fontes Primárias e História Literária pela UNESP, de Assis, e pós-doutora em Literatura e outras formas de saber pela USP, desenvolvendo pesquisa interdisciplinar entre literatura, comunicação e história. Doutora em Estudos Comparados de Literaturas de Língua Portuguesa pela USP. Mestre em Teoria Literária pela UNESP, de São José do Rio Preto. Licenciada em Letras (Português-Espanhol) pela UNESP, de São José do Rio Preto. Atua na Universidade Federal do Maranhão como professora adjunta da área de Literaturas de Língua Portuguesa, na Coordenação de Letras, do campus III; é docente permanente do Programa de Pós-Graduação em Cultura e Sociedade (PGCult), na linha de pesquisa Expressões e Processos Socioculturais. É líder do Grupo de Estudos e de Pesquisa Literatura, História e Imprensa (GEPELHI/UFMA), registrado no Diretório dos Grupos de Pesquisa do $\mathrm{CNPq}$, desenvolvendo projetos de pesquisa em fontes primárias, crítica textual e expressões e processos socioculturais.

Link Currículo Lattes:

http://buscatextual.cnpq.br/buscatextual/visualizacv.do?id=K4764767E1

\section{Diógenes André Vieira Maciel}

Possui graduação em Licenciatura Plena Em Letras pela Universidade Federal da Paraíba (1999) e doutorado em Letras pela Universidade Federal da Paraíba (2003). Atualmente é professor doutor - d da Universidade Estadual da Paraíba. Tem experiência na área de Letras, com ênfase em Letras, atuando principalmente nos seguintes temas: dramaturgia brasileira, teatro brasileiro, nacional-popular, drama moderno e classes subalternas. 


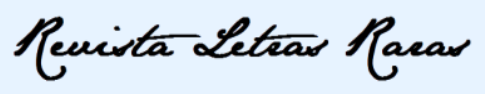

ISSN: 2317-2347 - v. 7, n. 1 (2018)

Link Currículo Lattes:

http://buscatextual.cnpq.br/buscatextual/visualizacv.do?id=K4761265J0

\section{Emanoel Cesar Pires de Assis}

Possui graduação em Letras Licenciatura em Português/ Inglês e respectivas literaturas, pela Universidade Estadual do Maranhão - UEMA Campus Caxias (2008). Mestre em Letras Estudos Literários - pela Universidade Federal do Piauí- UFPI. Doutorado em Literatura pela Universidade Federal de Santa Catarina - UFSC. Tem experiência na área de Letras, com ênfase em Teoria Literária e Literatura em Meio Digital. Atualmente, interessa-se pelo estudo de narrativas digitais, literatura brasileira contemporânea, ferramentas digitais para o ensino/aprendizagem de literatura e Teoria Literária. Líder do grupo de pesquisa CNPq: Literatura, Arte e Mídias - LAMID. Editor Gerente da Revista de Letras Juçara- UEMA.

Link Currículo Lattes:

http://buscatextual.cnpq.br/buscatextual/visualizacv.do?id=K4232533Y6

\section{Francimary Macêdo Martins}

Possui graduação em Letras (UEMA), Doutora em Linguística, com ênfase em Linguística Computacional e Linguística de Corpus (UFC); Mestre em TICs na Formação em EAD (UFC); Especialista em Língua Portuguesa e Literatura Brasileira (UFMA), Especialista em Educação a Distância (SENAC/RJ). É Professora-Adjunta da Universidade Federal do MA (UFMA), atuando no Departamento de Letras e no Núcleo de Educação a Distância (NEAD). Coordenadora Geral UAB/NEAD/UFMA. Membro do Conselho Deliberativo da Associação Brasileira de Estudos de Hipertexto e Tecnologias Educacionais (ABEHTE - 2016/2018. Tem experiência na área de Educação, com ênfase em Educação a Distância e Letras, atuando principalmente nos seguintes temas: Educação a Distância, TICs, Linguagens Tecnológicas, Tecnologias Educacionais, Linguística, Linguística Computacional, Linguística de Corpus, Hipertexto e Leitura Hipertextual, Leitura e Produção Textual, Língua Portuguesa e Educação em Engenharia.

Link Currículo Lattes:

http://buscatextual.cnpq.br/buscatextual/visualizacv.do?id=K4236936T8 


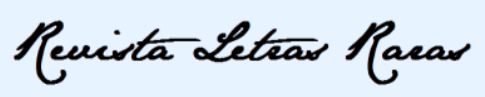

ISSN: 2317-2347 - v. 7, n. 1 (2018)

\section{Georgiana Márcia Oliveira Santos}

Possui graduação em Letras, pela Universidade Federal do Maranhão (2001), doutorado em Linguística, pela Universidade Federal do Ceará (2013), mestrado em Linguística, pela Universidade Federal do Ceará (2009), máster universitario en Lingüística Aplicada a la Enseñanza del Español como Lengua Extranjera, pela Universidad Europea del Atlántico (em andamento), especialização em Política de Igualdade Racial no Ambiente Escolar, pela Universidade Federal do Maranhão (2016), especialização em Educação do Campo, pela Universidade Estadual do Maranhão (2015), especialização em Gestão de Políticas Públicas em Gênero e Raça, pela Universidade Federal do Maranhão (2013), especialização em Docência do Ensino Superior, pela Universidade Cândido Mendes (2005), especialização em Libras, pela UNIASSELVI (em andamento).

Link Currículo Lattes:

http://buscatextual.cnpq.br/buscatextual/visualizacv.do?id=K4777079U8

\section{Heloísa Reis Curvelo Matos}

Doutora e Mestre em Linguística pela Universidade Federal do Ceará/UFC; Especialista em Linguística pela Universidade Federal do Maranhão/UFMA; fez parte da Equipe Técnica do Projeto: O léxico das plantas medicinais do nordeste: uma abordagem etnolinguística; Professora Pesquisadora do Atlas Linguístico do Maranhão - Projeto ALiMA/UFMA; Professora Pesquisadora do Atlas Linguístico do Brasil - ALIB; Professora de língua e literatura espanhola do curso de Letras da Universidade Federal do Maranhão/UFMA; foi Professora de Língua Portuguesa e Língua Espanhola do Ensino Médio da Rede Pública de Ensino do Estado do Maranhão; Professora colaboradora da Fundação Sousândrade de Apoio ao Desenvolvimento da Universidade Federal do Maranhão /FSADU; é Professora de Língua e Literatura Espanhola do curso de Letras da UFMA; foi Professora de Espanhol do Programa Nacional de Educação na Reforma Agrária - PRONERA/UFMA e de Linguística do Programa de Qualificação de Docentes-PQD da Universidade Estadual do Maranhão/UEMA.

Link Currículo Lattes:

http://buscatextual.cnpq.br/buscatextual/visualizacv.do?id=K4777315P6

\section{Ivete Maria Martel da Silva}

Possui graduação em Letras pela Universidade Federal do Maranhão-UFMA (1987), aperfeiçoamento em Língua Espanhola pela Universidad de Santander - Espanha (1998), mestrado em Ciência da Literatura (Teoria Literária) pela Universidade Federal do Rio de Janeiro-UFRJ (2001) e doutorado em Linguística e Língua Portuguesa pela Universidade Estadual Paulista-UNESP, Campos de Araraquara (2011). Atualmente é Professora Adjunta 


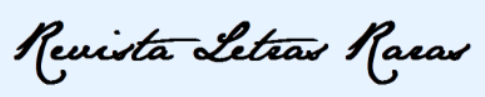

ISSN: 2317-2347 - v. 7, n. 1 (2018)

Nível I da Universidade Federal do Maranhão e Coordenadora do Projeto de Extensão Dom Quixote. Tem experiência na área de Letras, com ênfase em ensino-aprendizagem de língua espanhola, semântica enunciativa e literaturas de expressão hispânica.

Link Currículo Lattes:

http://buscatextual.cnpq.br/buscatextual/visualizacv.do?id=K4556670Z4

\section{João da Silva Araújo Júnior}

Doutor em linguística pela Universidade Federal do Ceará (UFC). Professor do Programa de Pós-Graduação em Letras/PGLETRAS, da Universidade Federal do Maranhão (UFMA). Professor do departamento de Letras da Universidade Federal do Maranhão (UFMA). Mestre em Linguística Aplicada pela Universidade Estadual do Ceará (UECE). Graduado em Letras pela Universidade Federal do Ceará (UFC). Graduado em Filosofia pelo Instituto Teológico e Pastoral do Ceará (ITEP). Líder do grupo de pesquisa em Linguagem e Tecnologia (LINTEC). Atua nas seguintes linhas de pesquisa: Linguística aplicada ao ensino e aprendizagem de línguas; avaliação e produção de materiais instrucionais de ensino de línguas; gêneros textuais digitais; gêneros textuais e hipertexto. Coordena os projetos de pesquisa "Tecnologias digitais e aprendizagem de línguas" e "O uso de aplicativos digitais na aprendizagem de línguas".

Link Currículo Lattes:

http://buscatextual.cnpq.br/buscatextual/visualizacv.do?id=K4500690H6

\section{José Dino Costa Cavalcante}

Possui graduação em Letras pela Universidade Federal do Maranhão (1995), mestrado na Universidade Estadual Paulista "Júlio de Mesquita Filho" (2000) e doutorado pela Universidade Estadual Paulista "Júlio de Mesquita Filho" (2005). Atualmente é professor adjunto do Departamento de Letras da Universidade Federal do Maranhão - UFMA. Tem experiência na área de Estudos Literários, com ênfase em Literatura Brasileira. Desenvolve pesquisas nas áreas de História da Literatura, Literatura e Sociedade e Literatura Maranhense. É membro permanente do corpo docente do Mestrado em Letras da UFMA. Sua linha de pesquisa é Literatura, História e Sociedade.

Link Currículo Lattes:

http://buscatextual.cnpq.br/buscatextual/visualizacv.do?id=K4773588U0 


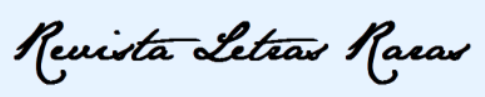

ISSN: 2317-2347 - v. 7, n. 1 (2018)

\section{Kelly Sheila Inocêncio Costa Aires}

Possuo Doutorado (2010) e Mestrado (2006) em Letras pela UFPB. Tenho licenciatura Plena em Letras pela UFCG (2004). De 1994 a 2004, atuei como professora da Educação Infantil e do Ensino Fundamental dos municípios de Pocinhos e de C. Grande - PB. Em 2006, fui professora de Metodologia da Pesquisa da FAVIP (Caruaru - PE). Desde 2006 sou professora de Educação Básica do Instituto Federal de Educação, Ciência e Tecnologia da Paraíba. De 2006 a 2012, lecionei Língua Portuguesa e Literatura no Ensino Técnico Integrado. De 2010 até hoje, atuo no Ensino Superior do IFPB. De 2013 a 2014, fui Coordenadora Adjunta da Rede e-Tec. De 2012 a 2018, produzi material didático para a EaD do IFPB (Letras e PFGC). De 2013 a 2015, coordenei a produção de Material Didático do IFPB. De 2015 a 2018, fui Coordenadora Adjunta do PIBID. Desde 2015, atuo no Estágio Supervisionado. Atualmente, ministro as disciplinas Literatura e Ensino, Literatura e Cultura Popular e Estágio no curso de Letras do IFPB - JP.

Link Currículo Lattes:

http://buscatextual.cnpq.br/buscatextual/visualizacv.do?id=K4736424A0

\section{Laura Dourado Loula Régis}

Possui graduação em Letras pela Universidade Federal de Campina Grande (2004), mestrado em Linguagem e Ensino pela Universidade Federal de Campina Grande (2007) e doutorado pelo Programa de Pós-graduação em Linguística (PROLING). É professora assistente na Universidade Federal de Campina Grande (UFCG). Tem experiência na área de Letras, com ênfase em Língua Portuguesa, atuando principalmente em temas referentes à Analise Linguística.

Link Currículo Lattes:

http://buscatextual.cnpq.br/buscatextual/visualizacv.do?id=K4772911J5

\section{Luciana Rocha Cavalcante}

Possui graduação em Letras pela Universidade Federal do Maranhão (1993), especialização em Leitura na Língua Inglesa pela Universidade Federal do Maranhão (1995), mestrado em Educação pela Universidade Federal do Maranhão (2003), doutorado pela Faculdade de Ciências e Letras - UNESP - Araraquara, em Linguística e Língua Portuguesa (2011) com pesquisa voltada para o ensino de línguas estrangeiras nos cursos de Licenciatura em Letras a distância com enfoque para a oralidade. Atualmente é Professora Adjunto da Universidade Federal do Maranhão. Tem experiência na área de Ensino/ Aprendizagem de línguas estrangeiras, com ênfase em Língua Inglesa. Atuando principalmente nos seguintes temas: prática docente, educação e ensino de línguas, educação a distância. 


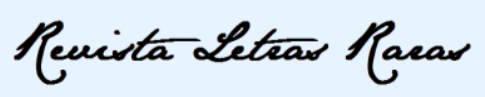

ISSN: 2317-2347 - v. 7, n. 1 (2018)

Link Currículo Lattes:

http://buscatextual.cnpq.br/buscatextual/visualizacv.do?id=K4238045H6

\section{Márcia Manir Miguel Feitosa}

Professora Titular do Departamento de Letras da Universidade Federal do Maranhão. Graduada em Letras pela Universidade Estadual de Campinas (1984), com Mestrado em Letras (Literatura Portuguesa) pela Universidade de São Paulo (1992) e Doutorado em Letras (Literatura Portuguesa) pela Universidade de São Paulo (1997). Pós-Doutora com bolsa CAPES, pelo Programa Ciência sem Fronteiras, em Estudos Comparatistas na Universidade de Lisboa, sob a supervisão da Profa. Helena Carvalhão Buescu. Docente permanente dos Programas de Mestrado em Letras, Linha de Pesquisa: Discurso, Literatura e Memória e em Cultura e Sociedade da UFMA, Linha de Pesquisa: Expressões e Processos Socioculturais. Líder do Grupo de Estudos de Paisagem em Literatura - GEPLIT. Vice-Líder do Grupo de Pesquisa em Estudos da Paisagem nas Literaturas de Língua Portuguesa. Tem experiência na área de Letras, com ênfase em Outras Literaturas Vernáculas.

Link Currículo Lattes:

http://buscatextual.cnpq.br/buscatextual/visualizacv.do?id=K4707741Y7

\section{Maria Aracy Bonfim Serra Pinto}

Professora Adjunta no Departamento de Letras da Universidade Federal do Maranhão onde ministra disciplinas de literaturas de língua inglesa. Integra como pesquisadora o Grupo de Pesquisa de Estudos Osmanianos e é autora do livro -Linha na roca, linha na pauta - o tecer da memória na obra O tempo e o vento, de Erico Verissimo - (2014, Editora CRV) e coorganizadora com Elizabeth Hazin e Francismar Ramírez Barreto dos livros "Palindromia", "Quem sou? Sou eu quem eu retrato [páginas mimeografadas à margem de A rainha dos cárceres da Grécia], "Números e nomes" pela Editora Siglaviva (Brasília). Participou, como organizadora, dos I, II, III e IV Encontros de Literatura Osmaniana em 2014, 2015, 2016 e 2017, respectivamente. Graduada em Letras, especialista em Inglês como Língua estrangeira. Mestre em Literatura Brasileira pela Universidade de Brasília. Doutora em Literatura Comparada, com a defesa da tese em intitulada "Indícios no insólito: Avalovara através do espelho", aprovada em 26 de outubro de 2015 pela Universidade de Brasília.

Link Currículo Lattes:

http://buscatextual.cnpq.br/buscatextual/visualizacv.do?id=K4734493Z6 


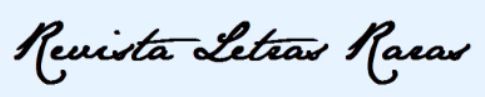

ISSN: 2317-2347 - v. 7, n. 1 (2018)

\section{Marize Barros Rocha Aranha}

Possui graduação em Letras pela Universidade Federal do Maranhão (1985), Mestrado em Educação pela Universidade Federal do Maranhão (2006) e Doutorado em Linguística e Língua Portuguesa pela UNESP - SP (2010). É professora adjunto IV da Universidade Federal do Maranhão. Foi Pró-Reitora de Extensão da UFMA de agosto de 2012 a outubro de 2015. Professora do Programa de Pós-Graduação em Letras (Mestrado Acadêmico) e do Programa de Pós-Graduação em Gestão de Ensino da Educação Básica (Mestrado Profissional). Participa do PROCAD/MELP - UFMA/USP. Possui pesquisas no campo da Linguística Cognitiva, da Análise do Discurso de linha francesa, em Metodologia do Ensino de Língua Portuguesa e em Formação de Professor de Língua Portuguesa.

Link Currículo Lattes:

http://buscatextual.cnpq.br/buscatextual/visualizacv.do?id=K4773493E5

\section{Monica Fontenelle Carneiro}

Graduada em Letras (Português/Inglês) pela Universidade Federal do Maranhão (UFMA), Especialista em Língua Inglesa e em Linguística Aplicada ao Ensino da Língua Materna e Estrangeira também pela UFMA, Mestre em Linguística pela Universidade Federal do Ceará (UFC) e Doutora em Linguística também pela UFC. Realizou estágio no Programa de Educação Continuada do Rhode Island College, em Providence/ RI, EUA, como Professora Visitante, e participou do Curso de Ensino a Distância em Países em Desenvolvimento do International Extension College no Instituto de Educação da Universidade de Londres como bolsista do governo britânico. Membro permanente do PGLetras - Programa de PósGraduação em Letras do Departamento de Letras da Universidade Federal do Maranhão. Professora do Departamento de Letras da Universidade Federal do Maranhão, com experiência nas áreas de Letras, Linguística e Linguística Aplicada e especial interesse em Linguística Cognitiva, Lingua(gem), Metáfora, Discurso e Ensino/Aprendizagem de Línguas.

Link Currículo Lattes:

http://buscatextual.cnpq.br/buscatextual/visualizacv.do?id=K4211880H2

\section{Neide de Fátima Cesar da Cruz.}

Professora Associado III da Universidade Federal de Campina Grande. Possui Pós-Doutorado e Doutorado pelo Programa de Pós-Graduação em Inglês: Estudos Linguísticos e Literários (PPGI), da Universidade Federal de Santa Catarina (UFSC), Doutorado Sandwich na Universidade de Birmingham, Inglaterra, durante o período de 01 ano como bolsista CAPES (07/2002 - 07/2003), Mestrado em Letras, Especialização em Língua Inglesa e Graduação em Licenciatura Plena em Letras pela Universidade Federal da Paraíba. Tem experiência na área 


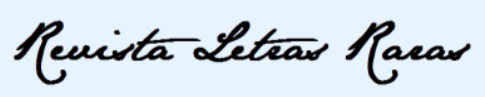

ISSN: 2317-2347 - v. 7, n. 1 (2018)

de Letras, com ênfase em Ensino e Aprendizagem de Língua Inglesa, especificamente compreensão e produção oral, e pronúncia do inglês. Tem trabalhado principalmente com os seguintes temas: aquisição de língua inglesa; inteligibilidade da pronúncia do inglês falado por brasileiros; inglês língua franca; compreensão e produção oral de professores em formação inicial.

Link Currículo Lattes:

http://buscatextual.cnpq.br/buscatextual/visualizacv.do?id=K4708202H9

\section{Sonia Maria Corrêa Pereira Mugschl}

Possui Graduação em Letras pela Universidade Federal do Maranhão (1978); Mestrado em Educação pela Universidade Federal do Maranhão (2003); Doutorado em Educação pela Faculdade de Educação da USP (2009); Pós-doutorado pela RUHR UNIVERSITÄT Bochum (2014). É Professora Doutora Associado IV da Universidade Federal do Maranhão. Professora Pesquisadora do Programa de Pós-Graduação em Letras (PGletras). Coordenadora do Grupo de Pesquisa GEPELL (Grupo de Estudo e Pesquisa em Língua e Literatura), trabalhando atualmente com o projeto intitulado: "O Português Brasileiro como Língua de herança: analisando as atividades e publicações sobre o Português Brasileiro na Europa". Membro da Academia Maranhense de Letras - (AML); Membro do Conselho Estadual de Educação - CEE-MA). Tem experiência na área de Letras, com ênfase em leitura e escrita, atuando, principalmente, nos seguintes temas: ensino, leitura, escrita, interdisciplinaridade, língua portuguesa, língua de herança e educação. Possui várias publicações sobre os temas citados.

Link Currículo Lattes:

http://buscatextual.cnpq.br/buscatextual/visualizacv.do?id=K4231779A7

\section{Viviane Dantas Moraes}

Professora adjunta I em Língua e Literatura francesa do Departamento de Letras na Universidade Federal do Maranhão (UFMA). Doutora em Estudos Literários pela Universidade Federal do Pará (2013-2017). Mestre em Estudos Literários (2009-2011) e licenciada em Letras com habilitação em Português/ Francês (1999-2005) pela Universidade Federal do Pará (UFPA). Tem especialização em Língua Portuguesa e Análise Literária pela Universidade da Amazônia (UNAMA), onde foi professora assistente no curso de Relações Internacionais (2011-2014). É pesquisadora integrante do grupo de pesquisa NARRARES Estudos de Narrativa de Resistência (CNPQ). 


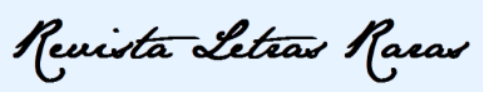

ISSN: 2317-2347 - v. 7, n. 1 (2018)

Link Currículo Lattes:

http://buscatextual.cnpq.br/buscatextual/visualizacv.do?id=K4254198Z9

\section{Washington Silva de Farias}

Possui graduação em Licenciatura em Letras pela Universidade Federal da Paraíba (1991), mestrado em Linguística pela Universidade Federal do Ceará (1998) e doutorado em Linguística pela Universidade Federal da Paraíba (2010). Atualmente é professor efetivo da Universidade Federal de Campina Grande. Tem experiência na área de Linguística, com ênfase em Análise do Discurso, atuando principalmente nos seguintes temas: constituição e representação discursiva de sujeitos e sentidos; discurso, memória e identidades; discurso, educação e ensino.

Link Currículo Lattes:

http://buscatextual.cnpq.br/buscatextual/visualizacv.do?id=K4770584Y4

\section{COLABORADORES}

\section{Jéssica Rodrigues Florêncio}

Graduada em Letras (Língua Portuguesa e Francesa) pela Universidade Federal de Campina Grande. Possui certificação em Proficiência no Ensino de LIBRAS pelo PROLIBRAS 2015/UFSC. Detém a atenção para os estudos sobre a literatura francófona, tendo realizado pesquisas mais específicas acerca da literatura francófona endereçada ao público infantojuvenil, com sua aplicação em sala de Francês como Língua Estrangeira (FLE). Atualmente tem focado seus estudos na produção literária de língua francesa do continente africano.

Link Currículo Lattes:

http://buscatextual.cnpq.br/buscatextual/visualizacv.do?id=K4314124P6

\section{Luana Costa de Farias}

É graduanda em Letras - Português e Francês pela Universidade Federal de Campina Grande (UFCG), onde é integrante do Programa de Educação Tutorial (PET) - Letras. Também é voluntária do Programa Institucional de Voluntariado em Iniciação Cientifica (PIVIC/CNPq) com o projeto A Poética Contemporânea da África francófona subsaariana escrita no 


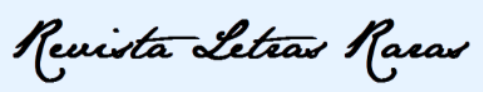

ISSN: 2317-2347 - v. 7, n. 1 (2018)

feminino. Também participa do programa de bolsas de extensão (PROBEX/UFCG) com o projeto de Ensino de línguas estrangeiras na infância: A Intercompreensão de Línguas Românicas como caminho para a diversidade linguística e cultural.

Link Currículo Lattes:

http://buscatextual.cnpq.br/buscatextual/visualizacv.do?id=K8861630P6

\section{Manuella Barreto Bitencourt}

Graduanda em Letras - Língua Portuguesa e Língua Francesa pela Universidade Federal de Campina Grande (UFCG); faz parte do Programa de Iniciação Científica (PIBIC/CNPQ) como bolsista, com os trabalhos intitulados Investigações Sobre A Literatura Francófona Magrebina Infanto-Juvenil Como Espaço Para Trocas Interculturais (2017) e Estudos Da Literatura Francófona Infanto-Juvenil Na Região Do Machrek (2018), os quais orientados pela Profa. Dra. Josilene Pinheiro-Mariz.

Link Currículo Lattes:

http://buscatextual.cnpq.br/buscatextual/visualizacv.do?id=K8669878P4

\section{Natielly Rosa da Silva}

Graduanda em Letras - Língua Portuguesa e Língua Francesa pela Universidade Federal de Campina Grande (UFCG); onde é integrante do Programa de Educação Tutorial (PET) Letras.

Link Currículo Lattes:

http://buscatextual.cnpq.br/buscatextual/visualizacv.do?id=K8382315P5 